\title{
Cervical Spine Myelopathy from Metalloma Association with Chronic Retention of a Bullet
}

\author{
Piyawat Bintachitt, M.D., Ratanaphorn Chamnan, M.D., Weera Chaiyamongkol, M.D., \\ Wongthawat Liawrungrueang, M.D.
}

Department of Orthopedics, Faculty of Medicine, Prince of Songkla University, Hat Yai, Songkhla 90110, Thailand.

Received 10 July 2020 • Revised 14 November 2020 • Accepted 17 November 2020 • Published online 16 April 2021

\begin{abstract}
:
A Civilian gunshot wound associated with metallosis in the cervical spine region was an extremely rare case; hence, the clinician had difficulty with diagnosis and surgical treatment.

A 57-year-old gentleman had a history of a gunshot wound injury going back 30 years. He presented with neck pain, progress of paresthesia of upper extremities and progressively difficult ambulation for 3 months. Radiographic and pathological diagnosis from tissue of the $7^{\text {th }}$ paravertebral of the cervical spine showed foreign bodies consistent with metallosis. The patient showed improvement of symptoms after posterior cervical spine fixation and decompression. He had full recovery at 1 year follow up.

Metallosis can occur in cases of chronic exposure to lead and metals. The results of this chronic process of metallosis will develop to metalloma, which then compresses the spinal cord and develops into myelopathy. The patient had a bullet, or piece of metal at the cervical spine, so surgical removal was performed to prevent further compression of the spinal cord from metalloma.
\end{abstract}

Keywords: cervical myelopathy, mettalloma, metallosis of the cervical spine

Contact: Piyawat Bintachitt, M.D.

Department of Orthopedics, Faculty of Medicine, Prince of Songkla University,

Hat Yai, Songkhla 90110, Thailand.

E-mail: piyabinta@hotmail.com

This is an open access article under the CC BY-NC-ND license

(http://www.jhsmr.org/index.php/jhsmr/about/editorialPolicies\#openAccessPolicy). 


\section{Introduction}

Civilian's gunshot injuries cause physical trauma from bullet(s) ejected from a firearm. The incidence of civilian gunshot wound-associated spinal cord injury (CGSWSCI) was $13.0 \%$ to $17.0 \%$ of all cases of spinal trauma. ${ }^{1-3}$ In the cervical region, the prognosis is poor in CGSWSCI. ${ }^{2,6}$ Surgical treatment includes neurologic deterioration; in a patient with neurological deficits, mechanical instability, metallic toxicity or bullet location having high risk of migration. ${ }^{7-9}$ The surgical intervention is very challenging for spinal surgeons for treatments; such as, removing the retained bullet, open decompression, adequate irrigation debridement gunshot's wound and cervical spinal fixation in unstable stability. The author presents the surgical management of patients, who initially have no neurologic deficits following a gunshot wound at the cervical spine region, but later developed progressive myelopathy and radiculopathy, secondary to metalloma, 30 years after the initial trauma. We report on this case, which presented at our institute in April, 2019.

\section{Case report}

A 57-year-old, Thai gentleman presented with neck pain and paresthesia of upper and lower extremities, with progressively difficult ambulation for 3 months. He had a history of a gunshot wound injury in the posterior aspect of the neck, dating back 30 years. At that time, irrigation and debridement of the wound was performed in a local hospital. The radiographic cervical spine film showed a $4.2 x$ 6.0 centimeter $(\mathrm{cm})$ metallic containing mass at the right side of the $7^{\text {th }}$ cervical spine to $1^{\text {st }}$ thoracic spine, with a few dense bullets (Figure 1A and Figure 1B). From computed tomography the cervical spine showed suspected metallosis involving C6 to T1 vertebrae and obliterated central spinal canal; the smaller size of the entire right vertebral artery and transverse foramina could be hypoplasia. Magnetic resonance imaging showed a large, intraosseous mass centered in the posterior column of $\mathrm{C} 7$ to $\mathrm{T} 1$ vertebral body, protruding to the spinal canal. This was causing spinal cord compression and myelopathy, metallosis from the retained bullet with metal deposits at the synovium and surrounded

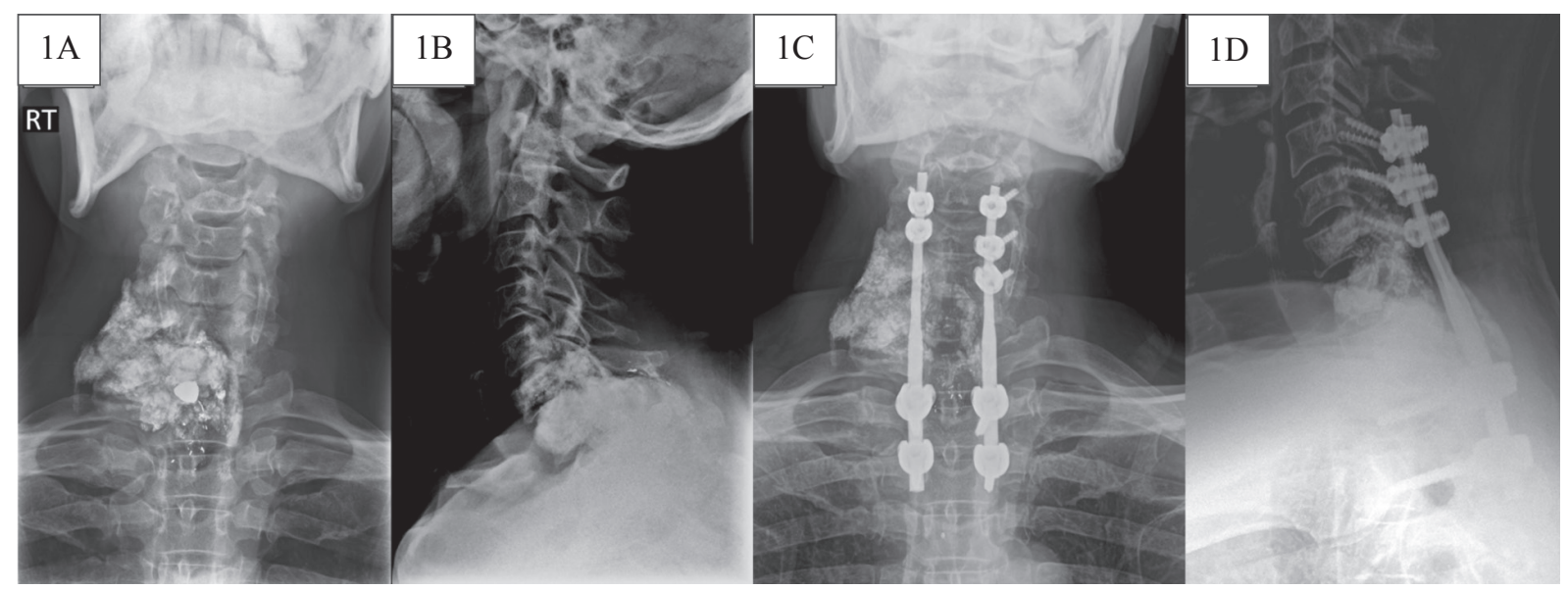

$\mathrm{RT}=$ right

Figure 1 Pre-operative radiographic films anteroposterior view (1A) and lateral view (1B), post-operative radiographic films anteroposterior view (1C) and lateral view (1D) 
soft tissue of the dura. Percutaneous biopsy at $C 7 / T 1$ was performed, and the results revealed fibrous connective tissue and muscle. The patient was taken under general anesthesia, and positioned in the prone position. The authors performed a posterior approach for laminectomy $\mathrm{C} 7 / \mathrm{T} 1$, with posterior stabilization from $\mathrm{C} 5$ to T2. The metal deposits, surrounded by the posterior element (Figure $2 \mathrm{~A}$ ) and dura (Figure 2B) were removed. The posterior stabilization was via the rods-screws system from C5 to T2 (Figure 2C). The bullet along with the foreign bodies (Figure 2D) were sent to a pathologist and forensic doctor for diagnosis. The report was a bullet and metal deposit in fibrous tissue from tissue $\mathrm{C} 7$. The final diagnosis was metalloma at the posterior cervical spine. Postoperative radiographic films showed alignment and good position of both the rods and pedicle screws (Figure $1 \mathrm{C}$ and Figure 1D). The patient showed improvement of symptoms after posterior cervical spine fixation, and decompression within 6 months.

After the patient was followed up at 1 year, his symptoms were improved; less neck pain and motor function had returned, the patient was also able to walk without gait aid. The author found that the patient was very satisfied with this treatment.

\section{Discussion}

CGSWSCI varies considerably, depending on the country, ranging from $13.0 \%$ to $44.0 \%$ of all cases of spinal trauma. ${ }^{1-3}$ Metallosis in the spinal canal is an extremely rare case. The process of wear on the metal debris, by interstitial fluid around the bullet and abnormal movement, resulted in an inflammatory reaction though the migration of macrophages. The chronic process of metallosis will develop to a granuloma formation called: "Metalloma". The inflammatory granulation tissue mass, or metalloma, developed from repetitive abnormal micromovements, or progressive reaction in a continuous, vicious cycle. ${ }^{4,5}$ The most reported treatment is decompression and internal fixation of the fracture form CGSWSCI. ${ }^{2,3,6,7}$ Additionally, the most common complications of metallosis in the longterm include: chronic pain, formation of abscess, lead poisoning (peripheral neuropathy, weakness, abdominal pain, arthralgia, and anorexia). ${ }^{8}$

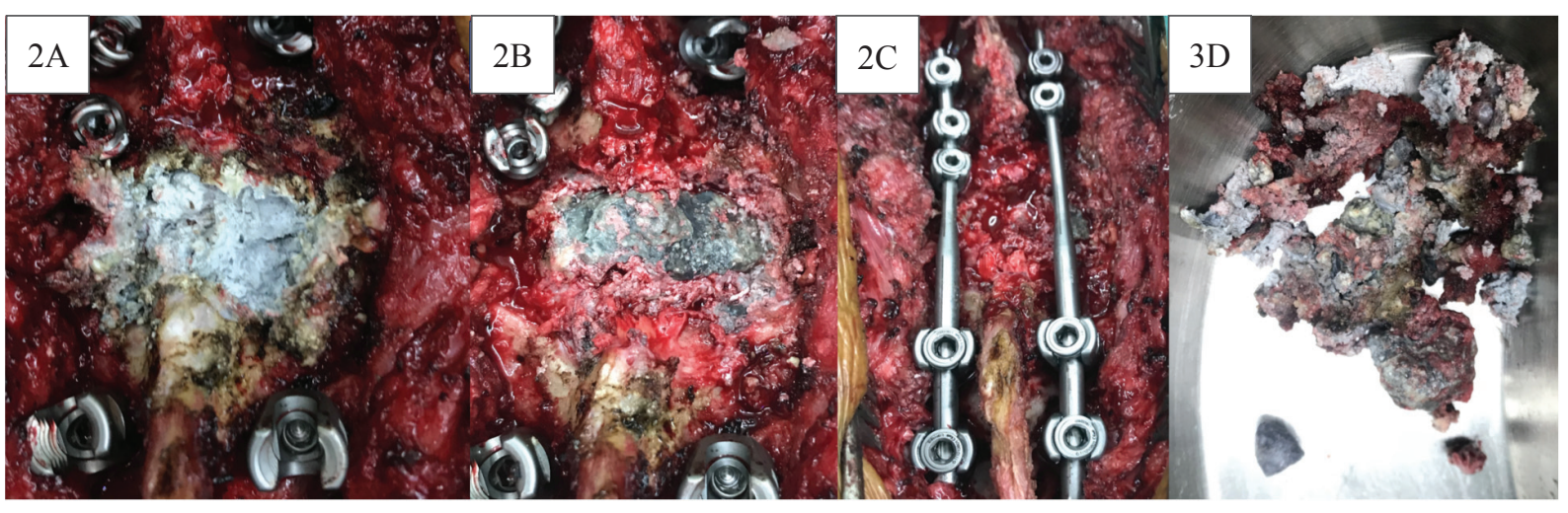

Figure 2 Intra-operative finding foreign bodies at the posterior element of C7/T1 (2A), foreign bodies surrounded the dura (2B), laminectomy $\mathrm{C} 7 / \mathrm{T} 1$ with posterior stabilization from $\mathrm{C} 5$ to $\mathrm{T} 2(2 \mathrm{C})$, and the bullet and foreign bodies (2D) 
In previous reviews, Machado et al. ${ }^{9}$ reported a successful outcome of spinal metallosis in the lumbar spine, in that the patient presented with progressive ambulation difficulty with a history of a firearm wound in the lumbar spine, 21 years ago; which had improvement of signs and symptoms after removal of metalloma and decompression of the spinal cord. Additionally, Womack et al. ${ }^{10}$ reported a successful surgical outcome for treatment of the heterotopic bone $(\mathrm{HO})$ formation of the cervical spine, after a gunshot wound. $\mathrm{HO}$ formation around retained bullet fragments at the left, lateral masses of C5-T1 were removed with posterior decompression and internal fixation. This treatment was similar to the author's case.

In this case, the patient had progressive cervical myelopathy, because of the result of the chronic process of metallic pieces, which developed into metalloma and compressed the spinal cord. The author preferred that the retained bullet, or metal at the cervical spine be surgically removed, so as to prevent further compression from metalloma.

\section{Conclusion}

Metallosis can occur in cases of chronic exposure to lead and other metals. The results of this chronic process of metallosis will develop into metalloma, which in turn, compresses the spinal cord and develops to myelopathy. In cases where the patient has a bullet or pieces of metal at the cervical spine, surgical removal should be performed to prevent further compression of the spinal cord from metalloma.

\section{References}

1. Farmer JC, Vaccaro AR, Balderston RA, Albert TJ, Cotler J. The changing nature of admissions to a spinal cord injury center: violence on the rise. J Spinal Disord 1998;11:400-3.

2. Chittiboina P, Banerjee AD, Zhang S, Caldito G, Nanda A, Willis BK. How bullet trajectory affects outcomes of civilian gunshot injury to the spine. J Clin Neurosci J Neurosurg Soc Australas 2011;18:1630-3.

3. Lin SS, Vaccaro AR, Reisch S, Devine M, Cotler JM, Reich SM. Low-velocity gunshot wounds to the spine with an associated transperitoneal injury. J Spinal Disord 1995;8:136-44.

4. Tezer M, Kuzgun U, Hamzaoglu A. Intraspinal metalloma resulting in late paraparesis. Arch Orthop Trauma Surg 2005;125:417-21.

5. Goldenberg Y, Tee JW, Salinas-La Rosa CM, Murphy M. Spinal metallosis: a systematic review. Eur Spine J 2016;25:1467-73.

6. Sidhu GS, Ghag A, Prokuski V, Vaccaro AR, Radcliff KE. Civilian gunshot injuries of the spinal cord: a systematic review of the current literature. Clin Orthop 2013;12:3945-55.

7. Waters RL, Sie IH. Spinal cord injuries from gunshot wounds to the spine. Clin Orthop 2003;3:120-5.

8. Cristante AF, de Souza FI, Barros Filho TEP, Oliveira RP, Marcon RM. Lead poisoning by intradiscal firearm bullet: a case report. Spine 2010;2:140-3.

9. Machado I, Gracia DP, Tannus CS, Tanaka K. Spinal metallosis as a complication of a lodgues bullet from a firearmwound: an image-centered case. Rev Assoc Med Bras (1992) 2018;64: 676-9.

10. Womack R, Luther E, Perez-Roman RJ, Manzano GR. Heterotopic bone formation 20 years after gunshot wound to the cervical spine: a rare cause of progressive cervical myelopathy in a previously asymptomatic patient. World Neurosurg 2019: 132:197-201. 